(c) 2020, The Authors. Published by FASS Inc. and Elsevier Inc. on behalf of the American Dairy Science Association ${ }^{\circledR}$. This is an open access article under the CC BY-NC-ND license (http://creativecommons.org/licenses/by-nc-nd/4.0/).

\title{
Genetic analysis of semen characteristic traits in young Norwegian Red bulls
}

\author{
H. B. Olsen, ${ }^{* 1} \odot$ B. Heringstad, ${ }^{1,2}{ }^{\circ}$ and G. Klemetsdal ${ }^{1}$ \\ ${ }^{1}$ Department of Animal and Aquacultural Sciences, Faculty of Biosciences, Norwegian University of Life Sciences, PO Box 5003, 1433 Aas, \\ Norway \\ ${ }^{2}$ Geno Breeding and Al Association, NO-2317 Hamar, Norway
}

\section{ABSTRACT}

The aim of this study was to estimate genetic parameters and genetic trends for male fertility in Norwegian Red bulls. We analyzed data on semen characteristics traits collected at the performance test station of young bulls from 1994 to 2016, in an andrology test used to ensure acceptable semen quality before being selected as an artificial insemination bull. Traits included were volume, concentration, and motility (percentage of moving sperm cells) in fresh samples and after storing for 24 and $48 \mathrm{~h}$, and sperm defects. The data consisted of 14,972 ejaculates from 3,927 young (11-15 mo) Norwegian Red bulls. Genetic parameters were estimated using bivariate linear animal models that included age in months, group-year, and collection-group (main effect of the interaction between ejaculate number and interval between collections) as fixed effects, and testday and additive genetic and permanent environment effect of the bull as random effects. Considerable genetic coefficients of variation were found for concentration and volume, with lower values for motility. Estimated heritabilities ranged from 0.02 and 0.03 (for sperm defects and motility in fresh samples) to 0.14 (volume and concentration measured on a continuous scale). All estimated genetic correlations were favorable, but the genetic correlations between volume and concentration and volume and sperm defects were not significantly different from zero. The genetic correlations between concentration and motility traits ranged from 0.53 to 0.83 , and those between volume and the motility traits were between 0.24 and 0.57 . All traits showed a slightly unfavorable genetic trend. Our results indicate that selection of bulls with better sperm quality is possible. Key words: andrology, genetic variation, heritability, genetic correlation, genetic trend

Received July 18, 2019.

Accepted August 27, 2019.

*Corresponding author: henriette.berg.olsen@nmbu.no

\section{INTRODUCTION}

In dairy, most focus has been given to female fertility, whereas male fertility has received much less attention. Male fertility refers to the behavior and libido of the bull, such as their eagerness to mount, as well as traits that describe the amount and quality of the semen they produce. Semen volume is made up of the sperm cells and the liquid that surrounds them. This liquid contains sugars and proteins and is an energy source for sperm cells on their journey through the female reproductive tract. To ensure gestation, millions of spermatozoa are released during ejaculation to ensure that one will reach and fertilize the egg, giving an advantage to highquality semen: ejaculates with a high concentration of sperm cells without defects and good overall motility (movement).

Heritability estimates of semen characteristics vary considerably both between and within traits. The varying results within traits may be due to factors such as differences in sample size, statistical modeling, population or breed, age and maturity of bulls, as well as how the traits are recorded and defined. Berry et al. (2014) performed a meta-analysis of male reproductive performance in dairy and beef cattle using results from 25 studies. Heritability estimates in the review ranged from 0.04 to 0.65 for volume, 0.10 to 0.56 for concentration, 0.01 to 0.51 for motility, and 0.07 to 0.35 for sperm abnormalities. The pooled mean heritability estimates obtained in the meta-analysis were moderate for volume (0.197), concentration (0.169), and sperm abnormalities (0.194), and low for motility (0.054). Later, Al-Kanaan et al. (2015) used data from an AI station (562 Holstein bulls, 10,341 records) to estimate genetic parameters for semen characteristic traits along a temperature and humidity gradient using a linear random regression model and obtained the following maximum heritability estimates: 0.18 for volume, 0.27 for concentration, and 0.29 for motility. With a similar data basis (787 bulls from 16 different breeds, 35,573 records), Berry et al. (2019) obtained heritability estimates of 0.20 for volume and concentration and 0.37 for motility. 
Berry et al. (2014) also reviewed genetic correlation estimates between semen characteristics, but references were few. The pooled mean estimates (standard errors, $\mathrm{SE}$ ) between volume and concentration, volume and motility, and concentration and motility were -0.16 (0.10), 0.06 (0.13), and $0.61(0.10)$, respectively. Further, motility correlated highly positive with a larger number of normal sperm cells in the sample: 0.87 (0.08).

For Norwegian Red, sperm quality is assessed for the first time at the performance test station when the bulls are around 12 mo old. Here, the libido of the young bulls is tested (mounting, propulsion, and protrusion), and several andrology traits are assessed to ensure acceptable semen quality. By achieving at least 3 out of 5 in an overall grade based on results from the andrology traits, bulls pass this test and may become an AI bull. Andrology test data from 1994 onward were available from the performance test station, and our aim was to use these data to estimate genetic parameters and genetic trend for semen characteristics in young Norwegian Red bulls.

\section{MATERIALS AND METHODS}

\section{Data and Traits}

Data on 6 semen characteristics traits (volume, concentration, motility, motility after storing for 24 and 48 $\mathrm{h}$, and sperm defects), which were routinely collected at the performance test station of young Norwegian Red bulls from 1994 to 2016, were made available by Geno Breeding and AI Association (Hamar, Norway). After a performance test on growth and conformation, promising bulls had their semen inspected to ensure acceptable semen quality before being selected as an AI bull (Geno, 2014).

Andrology testing was initiated by bulls being taken to another pen with other bulls to mount and become aroused. When a bull mounted within the pen, he was considered ready for semen collection. A phantom was tried first, while another bull was made available if this was not successful. Semen was collected in an artificial sheath when the bull had a satisfying erection. Average age at this test was 12 mo.

The collected ejaculates were stored at $38^{\circ} \mathrm{C}$ and analyzed within $2 \mathrm{~h}$ by trained technicians. Semen volume was measured directly from a scaled tube, and concentration was measured by using a spectrophotometer. Morphology of the sample was determined by visual inspection under a phase contrast microscope (magnification 100 to $400 \times$ ). Morphological abnormalities such as loose heads, tail defects, abnormal intermediate part, proximal droplets, and distal droplets were recorded if more than approximately $10 \%$ of a particular defect was detected in a sample. Because the frequency of collections with a recorded defect was low, we defined a binary trait as 1 if any defect was registered and 0 otherwise.

The phase contrast microscope was also used to assess the motility of the sample, a measurement of a sperm cell's ability to swim. Motility was assessed subjectively and given as the percentage of moving sperm cells, with $10 \%$ increments starting at 0 . After first inspection, samples were stored in a refrigerator until they were reactivated (heated to $38^{\circ} \mathrm{C}$ in $5 \mathrm{~min}$ ) and evaluated for motility again after $24 \mathrm{~h}$ and $48 \mathrm{~h}$. Because of the workload of the technicians, not all fresh samples were reevaluated after 24 or $48 \mathrm{~h}$.

Some changes in the management routines and laboratory equipment occurred during the period of data collection. Before the year 2000, bulls were kept in individual stalls instead of pens of 12 to 18 animals. Further, the spectrophotometer was replaced in March 2013. Until this date, the photometer used could not register concentrations $<390 \times 10^{6}$ spermatozoa $(\mathbf{s p z}) /$ $\mathrm{mL}$. Therefore, in this period, the concentration was set to $390 \times 10^{6}$ if the photometer showed 0 but sperm cells were found during microscope evaluation. Consequently, concentration was defined as 2 traits, before and after March 2013 (conc1 and conc2); conc2 was as recorded with the higher-resolution photometer, and conc1 was categorized into 10 classes: $0,1-390$, then in intervals of 200 , and finally $>1,790 \times 10^{6} \mathrm{spz} / \mathrm{mL}$.

The raw data included 16,780 semen collections. We required volume to be $>0$ to consider the other traits possible to score. Ejaculates with volume $>12 \mathrm{~mL}$ or concentration $>3,000 \times 10^{6} \mathrm{spz} / \mathrm{mL}$ were considered erroneous and removed (mean plus 6 and 8 times the standard deviation for volume and concentration, respectively). Further, 1,169 observations were duplicates and therefore removed.

Only bulls with information on group number and group year were kept. Group number and group year define the group and the year that bulls were sent off the station (either for slaughter or to the AI center). Finally, the analysis was carried out with bulls aged 320 to $473 \mathrm{~d}(10.5-15.5 \mathrm{mo})$ on the day of testing.

The final data set contained 14,972 semen collections from 3,927 bulls, with information on one or more of the following traits: volume, conc1, conc2, motility in fresh samples (mot0h), motility after storing for $24 \mathrm{~h}$ $(\boldsymbol{m o t} 24 \mathrm{~h})$, and $48 \mathrm{~h}(\boldsymbol{m o t} 48 \mathrm{~h})$, and sperm defects. The pedigree was traced back 4 generations and included 27,437 animals.

The number of andrology-tested bulls varied over time as shown in Figure 1A, with an overall average of 171 per year. The number of observations per bulls ranged from 1 to 11, and the mean varied over time 
as shown in Figure 1B. The number of observations per trait is given together with descriptive statistics in Table 1.

\section{Models}

Initially, the GLM procedure in SAS (version 9.4; SAS Institute Inc., Cary NC) was used to test whether group-year $(1, \ldots, 131)$, age in months $(10, \ldots, 15)$, and collection_n-interval (a fixed effect of combinations of ejaculate number $(1=$ first semen collection to 6 $=$ sixth or later collection) and number of days since previous collection $(1=1-4 \mathrm{~d}, 2=5-10 \mathrm{~d}$, and $3=$ $>10 \mathrm{~d})$ had a significant effect $(P \leq 0.05)$ on andrology traits. Group-year and age were significant for all traits, whereas collection_n-interval affected all traits except mot48h. Collection_n-interval was therefore not included in the model when estimating variance components for mot48h.

Estimation of (co)variance components were performed running bivariate linear animal models in DMU using the average information (AI)REML procedure (Madsen and Jensen, 2013). Standard errors of heritability and repeatability were calculated based on Taylor series expansion. Results from bivariate analyses (volume and each of the other traits) were used to estimate heritability and repeatability (formulas in Table 2 and 3 ), and bivariate models for each trait combination were used to estimate correlations between the semen characteristic traits. The following model was used:

$$
\begin{aligned}
{\left[\begin{array}{l}
\mathbf{y}_{1} \\
\mathbf{y}_{2}
\end{array}\right] } & =\left[\begin{array}{cc}
\mathbf{X}_{1} & 0 \\
0 & \mathbf{X}_{2}
\end{array}\right]\left[\begin{array}{l}
\mathbf{b}_{1} \\
\mathbf{b}_{2}
\end{array}\right]+\left[\begin{array}{cc}
\mathbf{Z t}_{1} & 0 \\
0 & \mathbf{Z t}_{2}
\end{array}\right]\left[\begin{array}{l}
\mathbf{t}_{1} \\
\mathbf{t}_{2}
\end{array}\right]+\left[\begin{array}{cc}
\mathbf{Z}_{1} & 0 \\
0 & \mathbf{Z a}_{1}
\end{array}\right]\left[\begin{array}{l}
\mathbf{a}_{1} \\
\mathbf{a}_{2}
\end{array}\right] \\
& +\left[\begin{array}{cc}
\mathbf{Z}_{1} & 0 \\
0 & \mathbf{Z} \mathbf{p}_{2}
\end{array}\right]\left[\begin{array}{l}
\mathbf{p}_{1} \\
\mathbf{p}_{2}
\end{array}\right]+\left[\begin{array}{l}
\mathbf{e}_{1} \\
\mathbf{e}_{2}
\end{array}\right]
\end{aligned}
$$

A
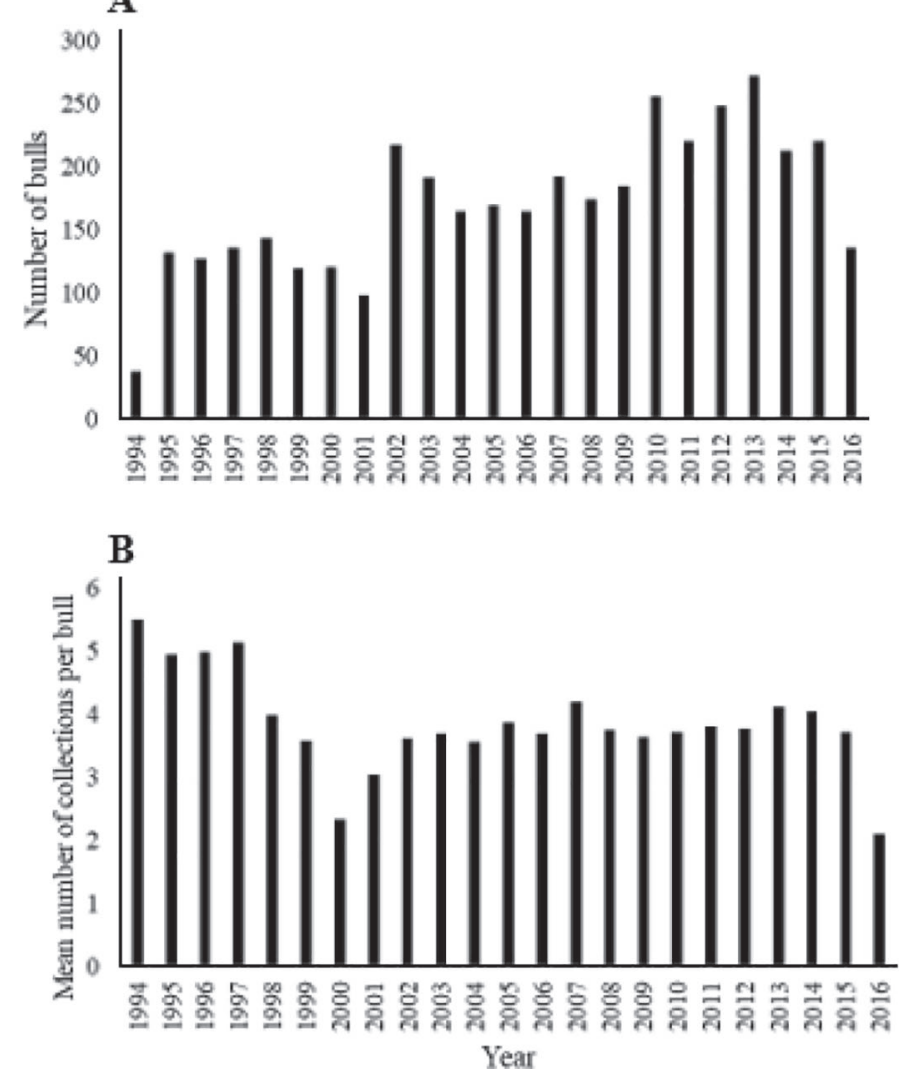

Figure 1. (A) Number of andrology tested bulls per year, and (B) average number of semen collections per bull from 1994 to 2016. First year of testing was used if the bulls were tested over $2 \mathrm{yr}$.

where $\mathbf{y}_{1}$ and $\mathbf{y}_{2}$ are vectors of observations for the 2 semen characteristic traits; $\mathbf{b}_{1}$ and $\mathbf{b}_{2}$ are vectors of the fixed effects for the 2 traits, including group-year, age, and collection_n_interval (the latter being excluded in the model for mot48h); $\mathbf{t}_{1}$ and $\mathbf{t}_{2}$ are vectors of the

Table 1. Descriptive statistics for the 7 semen characteristics traits

\begin{tabular}{lrrrcrr}
\hline Item & $\mathrm{n}$ & Mean & $\mathrm{SD}$ & Median & Minimum & Maximum \\
\hline Volume $(\mathrm{mL})$ & 14,963 & 2.6 & 1.5 & 2.5 & 0.5 & 12 \\
Conc1 $^{1}$ & 12,108 & 2.9 & 1.8 & 3 & 0 & 9 \\
Conc2 $^{2}$ & 2,844 & 475.3 & 306 & 440 & 0 & 1,745 \\
Mot0h $^{3}(\%)$ & 14,563 & 64.9 & 21.3 & 70 & 0 & 80 \\
Mot24h $^{3}(\%)$ & 10,035 & 61.2 & 19 & 70 & 0 & 80 \\
Mot48h $^{3}(\%)$ & 4,024 & 55.5 & 20.3 & 60 & 0 & 80 \\
Defects $^{4}$ & 14,972 & 0.04 & 0.18 & 0 & 0 & 1 \\
\hline
\end{tabular}

${ }^{1}$ Concentration recorded before March 2013 and categorized into 10 classes [0, 1-390, then increments of 200, and finally $>1,790 \times 10^{6}$ spermatozoa $\left.(\mathrm{spz}) / \mathrm{mL}\right]$.

${ }^{2}$ Concentration recorded after March 2013 given as $10^{6} \mathrm{spz} / \mathrm{mL}$.

${ }^{3}$ Motility in fresh samples $(0 \mathrm{~h})$ and after storing for 24 and $48 \mathrm{~h}$.

${ }^{4}$ Binary trait: scored as 1 if $>10 \%$ of a particular sperm defect was present in the sample, and 0 otherwise. Defects were loose heads, abnormalities in the tail or the intermediate part, distal droplets, and proximal droplets. 
Table 2. Additive genetic $\left(\sigma_{a}^{2}\right)$, permanent environmental $\left(\sigma_{p e}^{2}\right)$, test-day $\left(\sigma_{\text {test-day }}^{2}\right)$, and residual $\left(\sigma_{e}^{2}\right)$ variance components of the 7 semen characteristics traits together with their repeatability ${ }^{1}\left(c^{2}\right)$

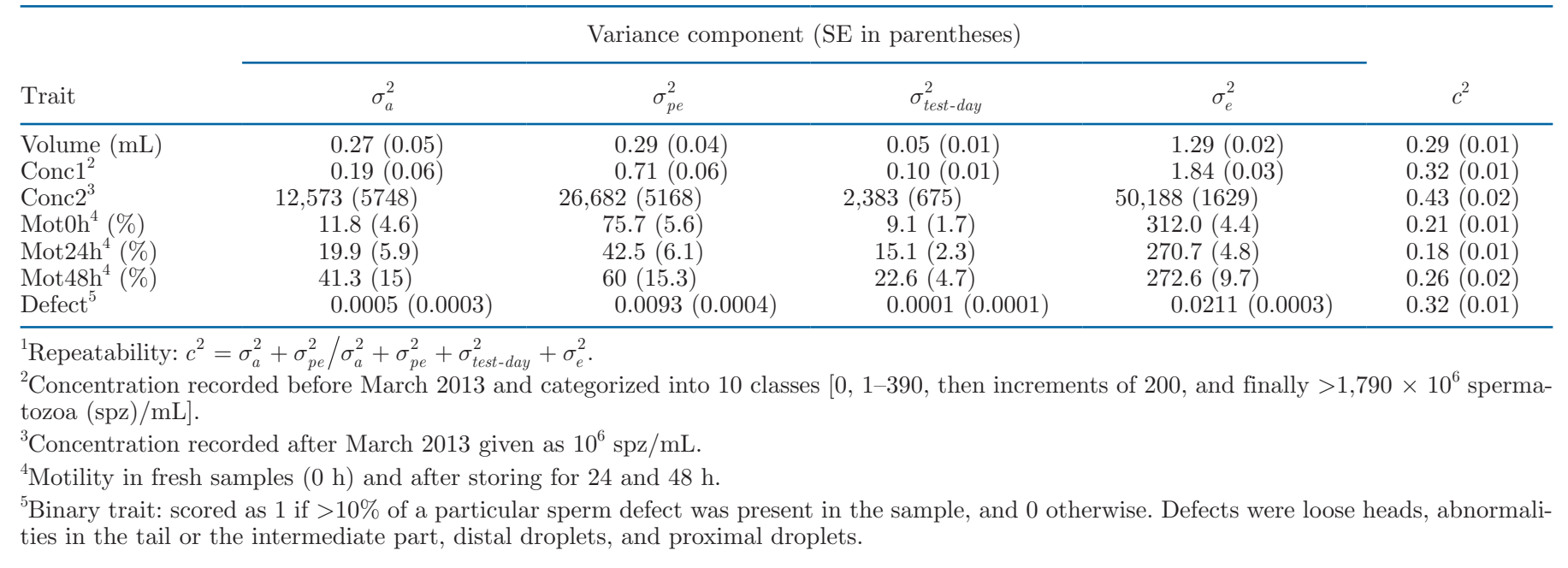

random test-day effects for the 2 traits; $\mathbf{a}_{1}$ and $\mathbf{a}_{2}$ are vectors of the random additive genetic effects of animal for the 2 traits; $\mathbf{p}_{1}$ and $\mathbf{p}_{2}$ are vectors of the random permanent environmental effects of bull for the 2 traits; $\mathbf{e}_{1}$ and $\mathbf{e}_{2}$ are vectors of the random residual effects for the 2 traits; and $\mathbf{X}, \mathbf{Z t}, \mathbf{Z a}$, and $\mathbf{Z p}$ are known incidence matrices connecting the observations to the corresponding fixed and random effects. The following assumptions were made for distribution of random effects:

$$
\begin{gathered}
{\left[\begin{array}{l}
\mathbf{t}_{1} \\
\mathbf{t}_{2}
\end{array}\right] \sim N\left[\left(\begin{array}{l}
0 \\
0
\end{array}\right), \mathbf{I} \otimes\left(\begin{array}{cc}
\sigma_{t_{1}}^{2} & \sigma_{t_{1} t_{2}} \\
\sigma_{t_{1} t_{2}} & \sigma_{t_{2}}^{2}
\end{array}\right)\right]} \\
{\left[\begin{array}{l}
\mathbf{a}_{1} \\
\mathbf{a}_{2}
\end{array}\right] \sim N\left[\left(\begin{array}{l}
0 \\
0
\end{array}\right), \quad \mathbf{A} \otimes\left(\begin{array}{cc}
\sigma_{a_{1}}^{2} & \sigma_{a_{1} a_{2}} \\
\sigma_{a_{1} a_{2}} & \sigma_{a_{2}}^{2}
\end{array}\right)\right],} \\
{\left[\begin{array}{l}
\mathbf{p}_{1} \\
\mathbf{p}_{2}
\end{array}\right] \sim N\left[\left(\begin{array}{l}
0 \\
0
\end{array}\right), \mathbf{I} \otimes\left(\begin{array}{cc}
\sigma_{p_{1}}^{2} & \sigma_{p_{1} p_{2}} \\
\sigma_{p_{1} p_{2}} & \sigma_{p_{2}}^{2}
\end{array}\right)\right]}
\end{gathered}
$$

and

$$
\left[\begin{array}{l}
\mathbf{e}_{1} \\
\mathbf{e}_{2}
\end{array}\right] \sim N\left[\left(\begin{array}{l}
0 \\
0
\end{array}\right), \mathbf{I} \otimes\left(\begin{array}{cc}
\sigma_{e_{1}}^{2} & \sigma_{e_{1} e_{2}} \\
\sigma_{e_{1} e_{2}} & \sigma_{e_{2}}^{2}
\end{array}\right)\right],
$$

where $\sigma_{t_{1}}^{2}, \sigma_{t_{2}}^{2}$, and $\sigma_{t_{1} t_{2}}$ are the test-day variance for the 2 traits and the test-day covariance between the 2 traits, respectively; $\sigma_{a_{1}}^{2}, \sigma_{a_{2}}^{2}$, and $\sigma_{a_{1} a_{2}}$ are the additive genetic variance for the 2 traits and the covariance between the 2 traits; $\sigma_{p_{1}}^{2}, \sigma_{p_{2}}^{2}$, and $\sigma_{p_{1} p_{2}}$ are the permanent environmental variance for the 2 traits and the covariance between the 2 traits; $\sigma_{e_{1}}^{2}, \sigma_{e_{2}}^{2}$, and $\sigma_{e_{1} e_{2}}$ are the residual variance for trait and the residual covariance between the 2 traits; $\mathbf{A}$ is the relationship matrix based on the 27,437 animals in the pedigree; and $\mathbf{I}$ is an identity matrix.

Breeding values were regressed on test-year (simple linear regression) to assess genetic time trends. The slopes were considered significantly different from 0 if the level of significance $(P)$ was $\leq 0.05$. To make it possible to compare the rate of genetic trends across traits, a measure of the relative change per trait was calculated as the ratio of the estimated slope of the regression line to the standard phenotypic deviation of the trait.

Because the data set included information on whether bulls were selected for AI afterward, and thus had passed the andrology test (or not), genetic trends were also estimated for approved and not-approved bulls.

\section{RESULTS}

\section{Descriptive Statistics and Distributions}

Volume ranged from 0.5 to $12 \mathrm{~mL}$ with a mean of 2.6 (Table 1), and the distribution was right skewed as shown in Figure 2A. About $70 \%$ of the samples were $\leq 3 \mathrm{~mL}$, and $95 \%$ of the collections contained $\leq 5 \mathrm{~mL}$. For the distribution of motility, most observations were 
Olsen et al.: GENETIC PARAMETERS OF ANDROLOGY TRAITS

Table 3. Heritability ${ }^{1}$ of the 7 semen traits on the diagonal and genetic correlations below (SE in parentheses)

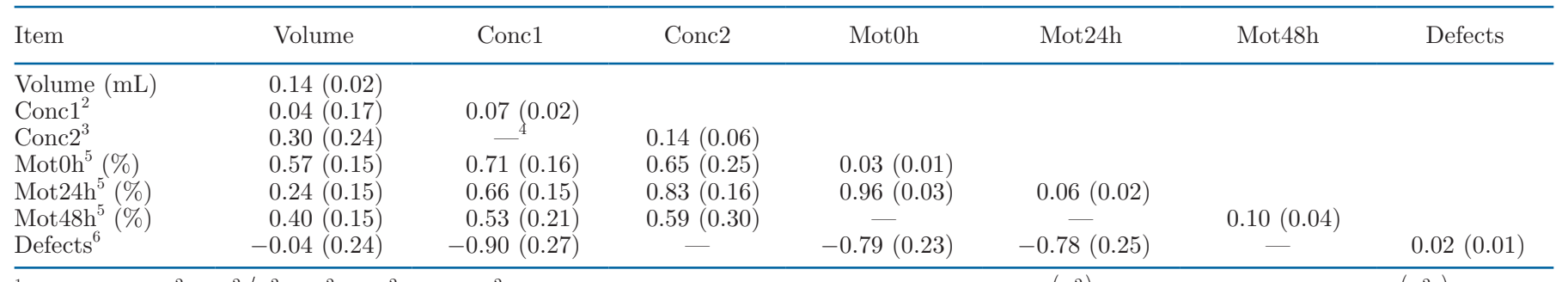

${ }^{1}$ Heritability: $h^{2}=\sigma_{a}^{2} / \sigma_{a}^{2}+\sigma_{p e}^{2}+\sigma_{\text {test-day }}^{2}+\sigma_{e}^{2}$, where variance components are additive genetic $\left(\sigma_{a}^{2}\right)$, permanent environmental $\left(\sigma_{p e}^{2}\right)$, test-day $\left(\sigma_{\text {test-day }}^{2}\right)$, and residual $\left(\sigma_{e}^{2}\right)$.

${ }^{2}$ Concentration recorded before March 2013 and categorized into 10 classes [0, 1-390, then increments of 200 , and finally $>1,790 \times 10^{6}$ spermatozoa $(\mathrm{spz}) / \mathrm{mL}]$.

${ }^{3}$ Concentration recorded after March 2013 given as $10^{6} \mathrm{spz} / \mathrm{mL}$.

${ }^{4}$ Analysis did not converge.

${ }^{5}$ Motility in fresh samples $(0 \mathrm{~h})$ and after storing for 24 and $48 \mathrm{~h}$.

${ }^{6}$ Binary trait: scored as 1 if $>10 \%$ of a particular sperm defect was present in the sample, and 0 otherwise. Defects were loose heads, abnormalities in the tail or the intermediate part, distal droplets, and proximal droplets.

on the right-hand side of the graph (Figure 2D). Table 1 shows that the average motility decreased from $65 \%$ when fresh to $55 \%$ after storing for $48 \mathrm{~h}$. At either time point, $80 \%$ was the highest motility measured, but considerably more of the fresh samples had this high level of spermatozoa movement (Figure 2D). Figures $2 \mathrm{~B}$ and $2 \mathrm{C}$ show the distribution of the 2 concentration measures, both with most observations on the left side. Only $5 \%$ of the samples evaluated for conc2 had concentrations $>10^{9} \mathrm{spz} / \mathrm{mL}$.

\section{Fixed Effects}

Generally, increasing age had a favorable effect on all traits (results not shown). From the solutions for group-year, a negative environmental trend was indicated for volume and conc1 (Figure 3A and B), among others. Further, volume increased with both ejaculate number and, in particular, length of interval between collections, whereas ejaculate number had an enlarging effect on conc1, conc2, mot0h, and mot24h (results not shown).

\section{Heritabilities and Repeatabilities}

Generally, the variance components were larger for the permanent environmental effect than for the additive genetic effect, which again was correspondingly larger than the variance component for day of testing (Table 2). The additive genetic standard deviation was $0.5 \mathrm{~mL}$ for volume and $112 \times 10^{6} \mathrm{spz} / \mathrm{mL}$ for conc2. The additive genetic standard deviation for motility increased from $3.4 \%$ in fresh samples to 4.5 and $6.4 \%$ after storing the sample for 24 and $48 \mathrm{~h}$, respectively. These estimates correspond with genetic coefficients of variation of $20 \%$ for volume, $23.6 \%$ for conc 2 , and $5.3,7.3$, and $11.6 \%$ for mot0h, mot $24 \mathrm{~h}$, and mot $48 \mathrm{~h}$, respectively.

Estimated repeatabilities were low to moderate (Table 2), with the subjectively evaluated motility traits being the lowest $(0.18-0.26)$. The Conc2 trait had the highest repeatability of all traits with 0.43 , whereas conc1, categorized into 10 classes, had somewhat lower repeatability (0.32), being equal to that of the defect trait. The repeatability of volume was 0.29.

The estimated heritabilities ranged from low to moderate (Table 2). Volume and conc2 had the highest heritabilities of 0.14 . Similar to the repeatability estimates, conc1 had lower heritability than conc2 $(0.07$ and 0.14 , respectively). The estimated heritability of motility increased from 0.03 in fresh semen to 0.06 and 0.10 after storing for 24 and $48 \mathrm{~h}$, respectively. Defects had the lowest heritability of all semen traits (0.02).

\section{Genetic Correlations}

All estimated genetic correlations were favorable (Table 3). Volume had the strongest genetic correlation with mot0h (0.57), whereas correlations with conc1 and defects were not significantly different from 0 . Overall, concentration had moderate or high genetic correlations with motility; the highest correlation was 0.83 between conc 2 and mot24h. Further, concentration was negatively genetically correlated with defects $(-0.90)$, meaning that a higher concentration was genetically associated with fewer defects. A higher motility (mot0h) also correlated genetically with fewer defects $(-0.79)$, and the motility in fresh samples was genetically very similar to motility after storing the semen for $24 \mathrm{~h}$, with a genetic correlation of 0.96 . 

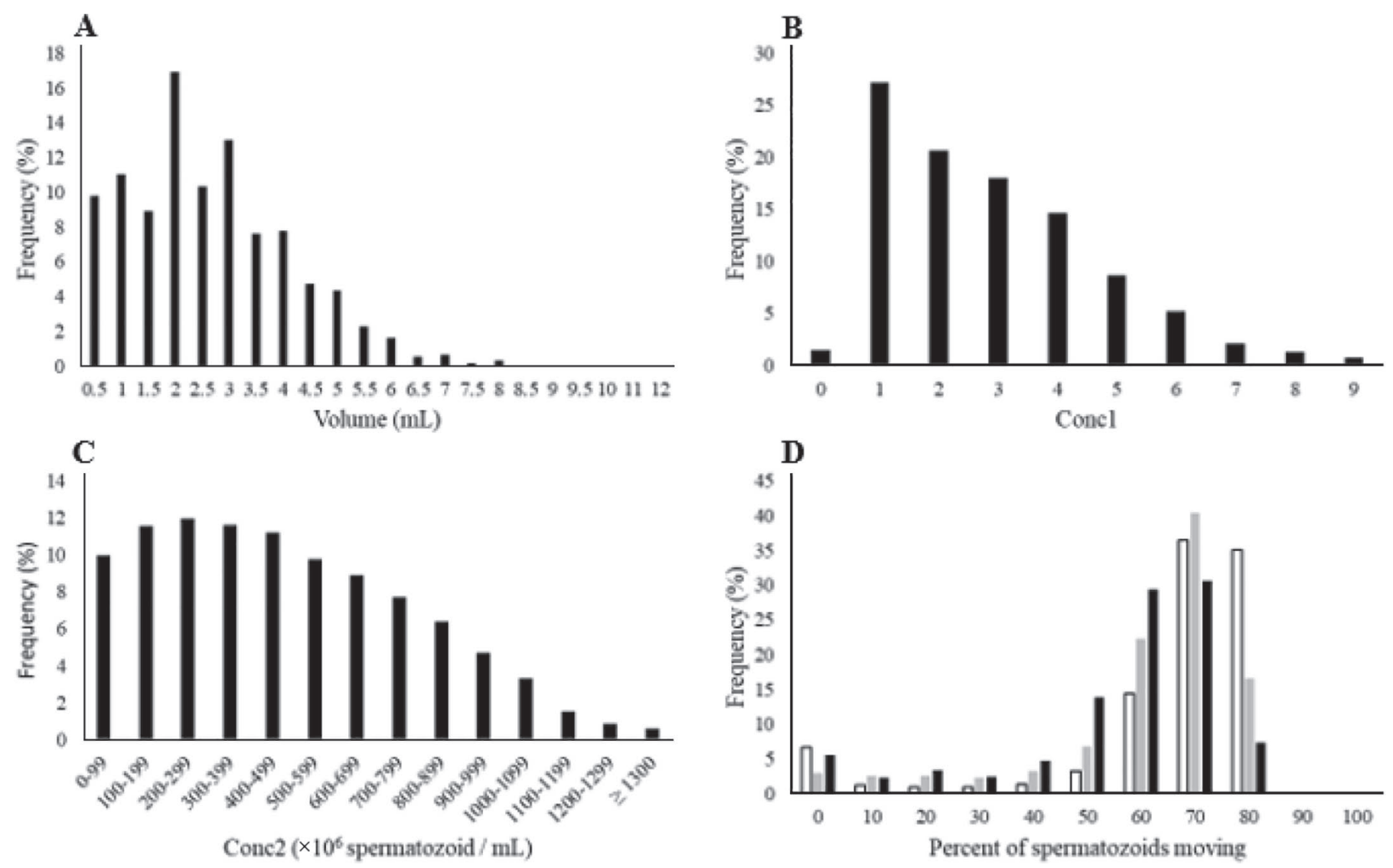

Figure 2. Distributions of (A) volume (mL), (B) concentration recorded before March 2013 and categorized into 10 classes [0, 1-390, then increments of 200, and finally $>1,790 \times 10^{6}$ spermatozoa $\left.(\mathrm{spz}) / \mathrm{mL}\right],(\mathrm{C})$ concentration recorded after March $2013 \mathrm{given}$ as $10^{6} \mathrm{spz} / \mathrm{mL}$, and $(\mathrm{D})$ motility in fresh samples (white bars), after storing for $24 \mathrm{~h}$ (gray) and $48 \mathrm{~h}$ (black).

\section{Genetic Trends}

All traits showed a significant $(P<0.05)$ slightly unfavorable genetic trend between 1994 and 2016 (Table 4). For the traits with phenotypes recorded for $>20$ yr, relative change (slope/SD), was largest for conc1 and mot24h and smallest for mot0h; defects were least affected.

\section{DISCUSSION}

The data set used in this analysis (14,972 observations from 3,927 bulls samples over more than $20 \mathrm{yr}$ ) is one of the largest analyzed for genetic parameters on sperm quality traits in dairy cattle. Generally, the heritabilities found in this study were in the lower range of those reported in the review by Berry et al. (2014). One reason for the low heritability estimates in our study might have been that the bulls were young, 10.5 to 15.5 mo old, and some of the youngest might have been prepubertal. In cattle, a commonly used definition of puberty is "the age at which an ejaculate contains 50 million spermatozoa with a minimum of $10 \%$ motility," because such an ejaculate can lead to pregnancy (Evans et al., 1996; Thundathil et al., 2016). In addition, bulls must have adequate sexual behavior and genital development to copulate and ejaculate. By following the above definition, all bulls in our data set fulfilled the second requirement because only records with volume $>0$ were kept; however, no requirement was set for the ejaculate to contain the minimum values required to meet the definition for puberty. It is important to note that Killian and Amann (1972) detected the first sperm when the bulls were $9 \mathrm{mo} \pm 3 \mathrm{wk}$, whereas they found puberty to occur as late as $10.25 \pm 1$ mo. Because one goal of andrology testing at the performance test station is to ensure that bulls sent to the AI center have adequate semen quality, knowing that the bulls have reached puberty before testing is essential to measure their true potential. This should therefore be a requirement before testing. Further, Chenoweth (1983) reviewed sexual behavior in bulls and concluded that techniques for sexual preparation such as restraint and false mounts can influence the semen characteristics 

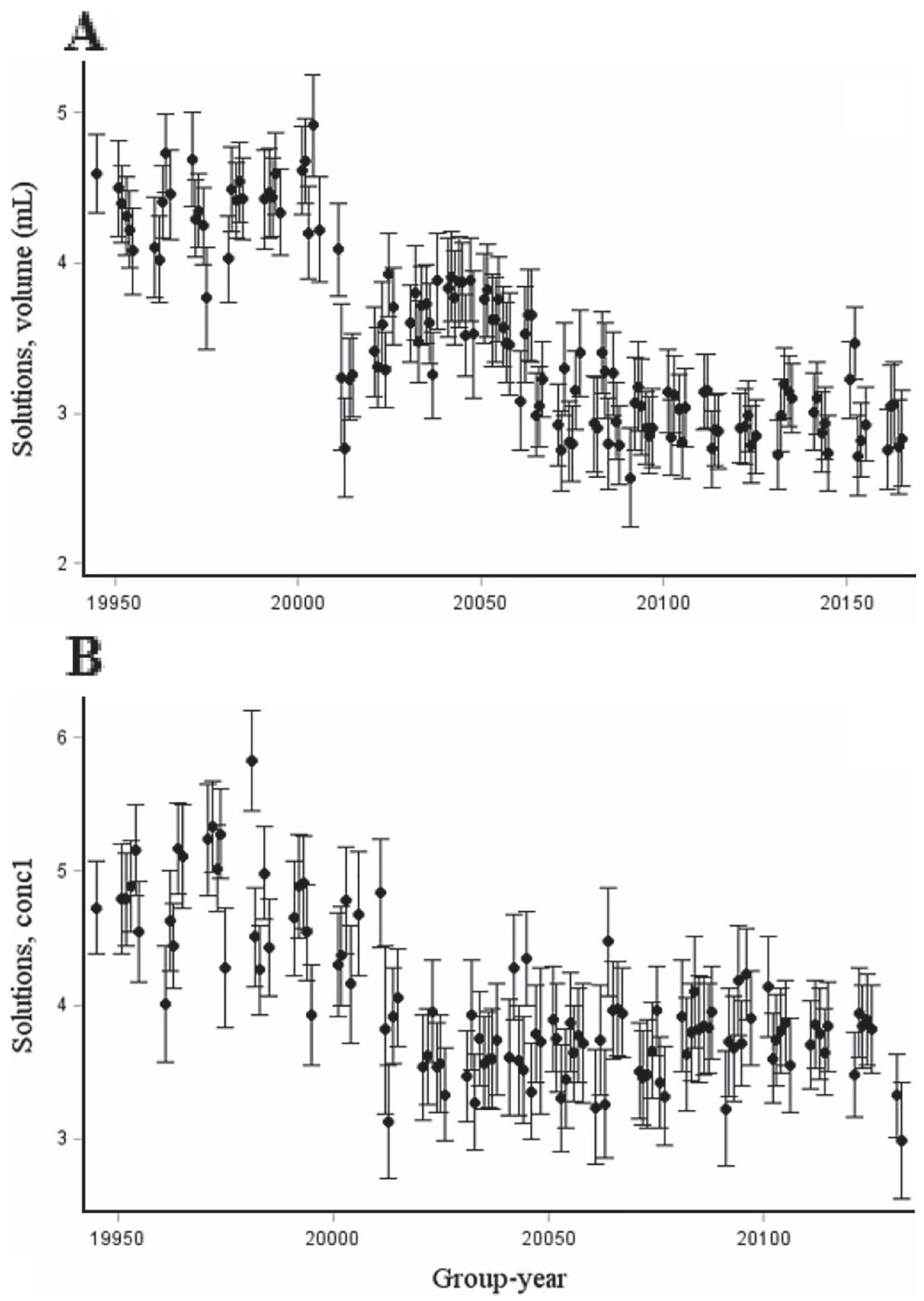

Figure 3. Fixed effect solutions for group-year (containing $\mu$ ) from bivariate analysis of $(\mathrm{A})$ volume $(\mathrm{mL})$ and $(\mathrm{B})$ conc1 [concentration recorded before March 2013 and categorized into 10 classes: 0, 1-390, then increments of 200, and finally $>1,790 \times 10^{6} \mathrm{spermatozoa}(\mathrm{spz}) / \mathrm{mL}$. Standard errors are plotted as whiskers. 
Table 4. Estimated genetic trend (1994-2016) for the 7 semen characteristics traits from regressing EBV on year, and the slope's level of significance $(P)$ of being different from 0

\begin{tabular}{|c|c|c|c|c|}
\hline Trait & Intercept & Slope & $P$-value & Slope/SD ${ }^{1}$ \\
\hline Volume $(\mathrm{mL})$ & 0.164 & -0.002 & 0.0124 & -0.0013 \\
\hline Conc1 $^{2}$ & 0.068 & -0.004 & $<0.0001$ & -0.0022 \\
\hline Conc $^{3}$ & 5.215 & -0.599 & $<0.0001$ & -0.0020 \\
\hline $\operatorname{Mot}^{4}{ }^{4}(\%)$ & 0.857 & -0.008 & 0.0464 & -0.0004 \\
\hline $\operatorname{Mot} 24 \mathrm{~h}^{4}(\%)$ & 2.103 & -0.047 & $<0.0001$ & -0.0025 \\
\hline $\operatorname{Mot} 48 \mathrm{~h}^{4}(\%)$ & 2.428 & -0.025 & 0.0003 & -0.0012 \\
\hline Defect $^{5}$ & -0.003 & 0.00002 & $<0.0001$ & 0.0001 \\
\hline
\end{tabular}

${ }^{1}$ Slope/phenotypic standard deviation of trait (from Table 1).

${ }^{2}$ Concentration recorded before March 2013 and categorized into 10 classes $\left[0,1-390\right.$, then increments of 200 , and finally $>1,790 \times 10^{6}$ spermatozoa $(\mathrm{spz}) / \mathrm{mL}]$.

${ }^{3}$ Concentration recorded after March 2013 given as $10^{6} \mathrm{spz} / \mathrm{mL}$.

${ }^{4}$ Motility in fresh samples $(0 \mathrm{~h})$ and after storing for 24 and $48 \mathrm{~h}$.

${ }^{5}$ Binary trait: scored as 1 if $>10 \%$ of a particular sperm defect was present in the sample, and 0 otherwise. Defects were loose heads, abnormalities in the tail or the intermediate part, distal droplets, and proximal droplets.

of the sample in dairy bulls. An improved protocol should consider a standardized preparation protocol for the bull rather than the current situation, in which bulls with insufficient erection are allowed several false mounts before semen collection. These changes, as well as measuring all traits on all semen collections, would likely enhance the value of these data for genetic means.

In our data, the mean volume and concentration (Table 1) were generally lower than results obtained by others (Ducrocq and Humblot, 1995; Mathevon et al., 1998b; Al-Kanaan et al., 2015; Berry et al., 2019). One cause for the low mean values was the change of housing of bulls in the year 2000, from tie stalls to group pens with 10 to 15 bulls in each. The effect of this change can be seen in the size of the group-year solutions that correct for changes in the station's management and routines over the years. Figure 3A shows the effect of group-year on volume. Although the effect varied among years, it tended to drop after the year 2000, and this tendency was similar for conc1 (Figure 3B). Pens with several bulls kept together allow them to mount each other and complete a full ejaculation within the pen. (E. Kummen, former head veterinary at Geno's performance test station, Øyer, Norway; personal communication, May 10, 2019). Moreover, sperm production is highly dependent on age of collection (Killian and Amann, 1972; Mathevon et al., 1998a; Al-Kanaan et al., 2015) and, as expected with young bulls that are still maturing, we found that increasing age had a favorable effect on all semen traits measured. After the onset of puberty, semen volume increases as scrotum and testicle size increase (Brito et al., 2002). In contrast to our results, Brito et al. (2002) did not find a significant effect of age on concentration or motility.
The bulls in their study, however, were considerably older than ours, with the youngest group consisting of bulls up to 36 mo of age. Mathevon et al. (1998a), however, found that concentration and motility increased up to approximately 22 mo of age, a finding supported by Al-Kanaan et al. (2015). In addition to group-year and age, we estimated the joint effect of ejaculate number and days since last collection. Volume increased with increasing ejaculate number, and even more so with a longer interval between collections. This is in agreement with Mathevon et al. (1998a), Fuerst-Waltl et al. (2006), and Al-Kanaan et al. (2015). They all reported the highest volume with the longest interval between collections. For concentration and motility (except mot48h), increased ejaculate number enhanced all variables, whereas interval was less important. In contrast to our findings, Karoui et al. (2011) and Fuerst-Waltl et al. (2006) found a higher concentration in the first ejaculate, whereas motility was nearly unaffected or lower in the first ejaculate. Note that in those studies "ejaculate number" refers to the number of ejaculates taken on the same day, whereas in our study, it was the number of ejaculates that a bull has ever given, and therefore includes the effect of the bulls' increased experience and familiarity with the test. A lack of consensus exists on whether the interval length affects motility. Everett et al. (1978), Mathevon et al. (1998a), and Berry et al. (2019) all found that interval length was statistically significant for motility, but whereas the latter authors could not find a clear trend, Mathevon et al. (1998a) found that the shortest interval $(2 \mathrm{~d})$ gave the highest percentage of motility in the samples. In contrast, Al-Kanaan et al. (2015) did not find a significant effect of interval on motility, whereas Fuerst-Waltl et al. (2006) found a significant effect on progressive motility, but not on motility score.

As mentioned earlier, the heritability estimates obtained from our data (Table 2) were somewhat lower than the pooled mean heritability estimates from the meta-analysis performed by Berry et al. (2014), but all estimates, except for sperm defects, were within the large range of heritability estimates found in the literature. The heritability of volume in our study was estimated to be 0.14 , which is lower than the meta-analysis estimate of 0.20 (Berry et al., 2014), but between the heritability estimates found in 2 studies conducted by Mathevon et al. (1998a,b) analyzing performance test-station data for Holstein and French Montbéliarde bulls, respectively (0.24 and 0.08). We estimated the heritability of conc2 and motility in fresh samples to be 0.14 and 0.03 , respectively, which is close to the findings of Berry et al. (2014; 0.17 and 0.054). The heritability of conc2 was larger than that for conc1 (0.07), likely because some information was lost due to the 
categorization of conc1, and conc1 being less accurately measured because of the lower-resolution photometer used, especially for values between 0 and $390 \times 10^{6}$ $\mathrm{spz} / \mathrm{mL}$. In contrast to volume and concentration, which were recorded objectively, motility was recorded subjectively. This less accurate measurement is likely to result in lower heritability. Interestingly, storage of semen resulted in higher heritability for motility compared with that of fresh samples. In the literature, however, motility after thawing is the commonly examined challenge trait. Because frozen semen is usually used in Norwegian Red, and we do not know whether semen that tolerates storing also tolerates freezing, the importance of the storage challenge is difficult to evaluate at the current time. Motility in the literature may refer to motility score (from bad to good) or the percent of cells that move as measured by trained technicians or by computer-assisted sperm analysis (CASA). In addition to differences in statistical models, populations, and breeds, different trait definitions can explain some of the variation in heritability estimates found for motility in the literature. Among the 7 semen characteristic traits analyzed in this study, sperm defect contained the least amount of genetic information, with an estimated heritability of 0.02 . This is lower than heritability estimates for sperm abnormality found in the literature, which ranged from 0.07 to 0.35 (Ducrocq and Humblot, 1995; Kealey et al., 2006; Corbet et al., 2013). In those studies, sperm abnormalities were measured on a continuous scale as the percent of sperm with a defect in a sample. In our study, the trait was treated as binary and the frequency of collections registered with a defect was low, which resulted in the low heritability estimate. We chose to analyze all traits using linear models, although a threshold model would have been theoretically more appropriate for sperm defects, being a binary trait.

All genetic correlations were favorable, in the sense that a genetic improvement in any of the traits would also improve the others as a correlated selection response. We were not able to estimate the genetic correlation between conc1 and conc2, because very few bulls had information on both traits, and the analyses did not converge. However, the genetic correlations between these traits and either of the remaining ones were similar and little affected by the categorization of conc1. The genetic correlation between mot0h and mot $24 \mathrm{~h}$ was close to 1 , meaning that motility in fresh and storage-challenged samples can be considered genetically much the same trait. The genetic correlations between concentration and motility in fresh samples were high and favorable (0.65-0.71), which is in agreement with Berry et al. (2014) and Karoui et al. (2011), who found estimates of 0.61 and 0.54 , respectively. The genetic correlations between volume and the 3 motility traits ranged from 0.24 to 0.57 , being highest in fresh samples and larger than those reported by Berry et al. (2014) and Karoui et al. (2011) (0.06-0.13). Further, we found volume and conc1 and conc2 to have little or no genetic correlation (0.04 and 0.30 , respectively), whereas most studies have found a negative genetic correlation between these 2 traits (Karoui et al., 2011; Berry et al., 2014, 2019). Volume, concentration, and motility were found to be negatively correlated with sperm defects $(-0.04$ to -0.90$)$, which is favorable and means that a genetic increase in the traits mentioned results in fewer defects in the sample as a correlated response.

Over the period from 1994 to 2016, all traits showed a slightly unfavorable genetic trend (Table 4 ), with a slope of the linear regression being significantly $(P<$ $0.05)$ different from zero. The relative largest genetic changes for traits recorded $>20 \mathrm{yr}$ were found for conc 1 and mot24h, whereas mot0h and defects seemed to be least affected. The EBV for volume plotted in Figure 4 show the regression line for the selected bulls to generally lie above that for unselected bulls, but the difference is very small. Corresponding results were obtained for conc1 and mot0h. The small difference between selected and unselected bulls is likely due the low heritability of the 7 traits, but particularly the low selection intensity that can be practiced for these traits at the performance test. Thus, andrology testing and the minimum semen quality requirement before selection of AI bulls were not sufficient to genetically improve semen volume or quality over time. Likely, the unfavorable genetic trends were correlated selection responses caused by selection on traits that are genetically correlated with andrology. The genetic relationship between andrology and other traits is not well known (Berry et al., 2014). Thus, there is a need to examine the genetic association between male fertility and production traits, health traits, and cow fertility in Norwegian Red and other populations.

This study demonstrated the need to intensify selection for improved semen quality in the future. One obvious solution is to base selection on genomic breeding values that are already available when recruiting bull calves and updated throughout the performance testing. This should have the potential to achieve a positive selection differential in semen traits. For this to be possible, andrology testing must continue, preferably with the recommendations stated previously with standardized preparations of bulls known to have reached puberty, as well as measuring all traits on all semen collections. Moreover, research should examine the genetic relationship between the andrology traits in the performance test and at the AI center. A special focus should 


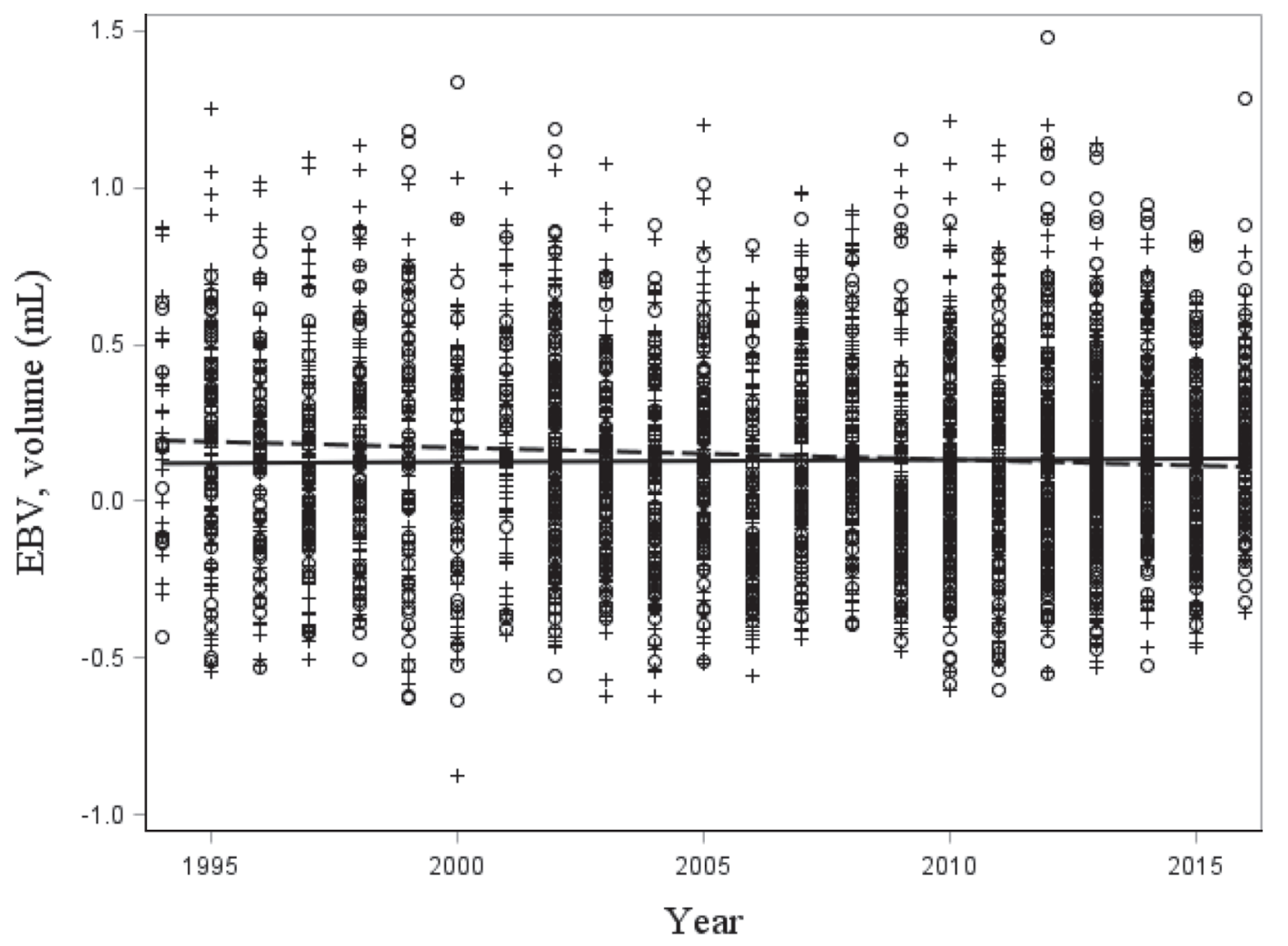

Figure 4. Estimated breeding values of volume for the bulls that were approved for AI production $(+)$ and those that were not $(\bigcirc)$. Both group's EBV were regressed on year to estimate genetic trend for selected (solid line) and unselected (dashed line) bulls.

be given to determine the genetic association between motility after thawing and storage-challenged motility at the performance test. Following these guidelines, it should be possible to select AI bulls with better semen quality in the future.

\section{CONCLUSIONS}

Using a large data set sampled over $\geq 20$ yr with 14,472 records on almost 4,000 bulls that were unselected with respect to andrology, genetic variation was estimated for all 7 examined traits. The genetic coefficient of variation was largest for concentration (23.6\%), followed by volume $(20 \%)$, and was lower for motility in fresh samples (5.3\%). Heritability estimates were low to moderate $(0.02-0.14)$ and in the same order as that for genetic variance. The size of the data set allowed for precise estimates of genetic correlations between traits, all of which were found to be favorable. The genetic trends were slightly unfavorable for all traits, which implies that phenotypic selection with the current intake regimen to the AI station does not ensure a positive genetic trend of andrology traits in Norwegian Red bulls. The lack of antagonistic relationship between traits and the amount of genetic variance within traits indicate that selection for these traits is possible. Using genomic breeding values for the traits when buying bulls for the performance test station is recommended to reverse the unfavorable genetic trends found in this study.

\section{ACKNOWLEDGMENTS}

Thanks to Geno (Hamar, Norway) for giving access to data, and to The Research Council of Norway, Oslo, for funding (project number: NRF-255097/E50).

\section{REFERENCES}

Al-Kanaan, A., S. König, and K. Brügemann. 2015. Effects of heat stress on semen characteristics of Holstein bulls estimated on a continuous phenotypic and genetic scale. Livest. Sci. 177:15-24. https://doi.org/10.1016/j.livsci.2015.04.003.

Berry, D. P., B. Eivers, G. Dunne, and S. McParland. 2019. Genetics of bull semen characteristics in a multi-breed cattle population. Theriogenology 123:202-208. https://doi.org/10.1016/j.theriogenology 2018.10.006.

Berry, D. P., E. Wall, and J. E. Pryce. 2014. Genetics and genomics of reproductive performance in dairy and beef cattle. Animal 8:105-121. https://doi.org/10.1017/S1751731114000743.

Brito, L. F., A. E. D. Silva, L. Rodrigues, F. Vieira, L. A. Deragon, and J. Kastelic. 2002. Effect of age and genetic group on characteristics of the scrotum, testes and testicular vascular cones, and on sperm production and semen quality in AI bulls in Bra- 
zil. Theriogenology 58:1175-1186. https://doi.org/10.1016/S0093 $-691 x(02) 00921-4$.

Chenoweth, P. J. 1983. Sexual behavior of the bull: A review. J. Dairy Sci. 66:173-179. https://doi.org/10.3168/jds.S0022-0302(83)81770 -6 .

Corbet, N. J., B. M. Burns, D. J. Johnston, M. L. Wolcott, D. H. Corbet, B. K. Venus, Y. Li, M. R. McGowan, and R. G. Holroyd. 2013. Male traits and herd reproductive capability in tropical beef cattle. 2. Genetic parameters of bull traits. Anim. Prod. Sci. 53:101-113. https://doi.org/10.1071/AN12163.

Ducrocq, V., and P. Humblot. 1995. Genetic characteristics and evolution of semen production of young Normande bulls. Livest. Prod. Sci. 41:1-10. https://doi.org/10.1016/0301-6226(94)00029-7.

Evans, A. C. O., R. A. Pierson, A. Garcia, L. M. McDougall, F. Hrudka, and N. C. Rawlings. 1996. Changes in circulating hormone concentrations, testes histology and testes ultrasonography during sexual maturation in beef bulls. Theriogenology 46:345-357. https: //doi.org/10.1016/0093-691x(96)00190-2.

Everett, R. W., B. Bean, and R. H. Foote. 1978. Sources of variation of semen output. J. Dairy Sci. 61:90-95. https://doi.org/10.3168/ jds.S0022-0302(78)83555-3.

Fuerst-Waltl, B., H. Schwarzenbacher, C. Perner, and J. Sölkner. 2006. Effects of age and environmental factors on semen production and semen quality of Austrian Simmental bulls. Anim. Reprod. Sci. 95:27-37. https://doi.org/10.1016/j.anireprosci.2005.09.002.

Geno. 2014. Geno performance test station at Øyer. Accessed Aug. 12, 2019. https://www.geno.no/globalassets/geno-sa/02_dokumenter/ 06_om-geno/brosjyrer/oyer-brosjyre-eng-nov-2014.pdf

Karoui, S., C. Díaz, M. Serrano, R. Cue, I. Celorrio, and M. J. Carabaño. 2011. Time trends, environmental factors and genetic basis of semen traits collected in Holstein bulls under commercial conditions. Anim. Reprod. Sci. 124:28-38. https://doi.org/10.1016/j .anireprosci.2011.02.008
Kealey, C. G., M. D. Macneil, M. W. Tess, T. W. Geary, and R. A. Bellows. 2006. Genetic parameter estimates for scrotal circumference and semen characteristics of Line 1 Hereford bulls. J. Anim. Sci. 84:283-290.

Killian, G. J., and R. P. Amann. 1972. Reproductive capacity of dairy bulls. IX. Changes in reproductive organ weights and semen characteristics of Holstein bulls during the first thirty weeks after puberty. J. Dairy Sci. 55:1631-1635. https://doi.org/10.3168/jds .S0022-0302(72)85731-X.

Madsen, P., and J. Jensen. 2013. A User's Guide to DMU. A Package for Analysing Multivariate Mixed Models. Version 6, release 5.2. Aarhus University, Aarhus, Denmark.

Mathevon, M., M. M. Buhr, and J. C. M. Dekkers. 1998a. Environmental, management, and genetic factors affecting semen production in Holstein bulls. J. Dairy Sci. 81:3321-3330. https://doi.org/ 10.3168/jds.S0022-0302(98)75898-9.

Mathevon, M., J. C. Dekkers, and M. Buhr. 1998b. Environmental, management and genetic factors affecting semen production in French Montbéliard bulls. Livest. Prod. Sci. 55:65-77. https://doi .org/10.1016/S0301-6226(98)00116-X.

Thundathil, J. C., A. L. Dance, and J. P. Kastelic. 2016. Fertility management of bulls to improve beef cattle productivity. Theriogenology 86:397-405. https://doi.org/10.1016/j.theriogenology.2016.04 .054 .

\section{ORCIDS}

H. B. Olsen () https://orcid.org/0000-0002-0831-793X

B. Heringstad $\odot$ https://orcid.org/0000-0001-7388-3893 